\title{
Novel Extraction Method to Produce Active Solutions from Plant Materials
}

\author{
R. Abel C. Torres, Diego T. Santos, M. Angela A. Meireles* \\ LASEFI/DEA/FEA (School of Food Engineering)/UNICAMP (University of Campinas), Cidade Universitária "Zeferino Vaz", \\ R. Monteiro Lobato, Campinas, SP, Brazil
}

\begin{abstract}
A novel selective extraction method to produce active solutions with from plant materials was developed. Named by our research group as High Turbulence Extraction Assisted by Ultrasound (HTEAU) the feasibility of this process was demonstrated using semi-defatted annatto seeds (Bixa orellana L.) as a model plant material and ethanol as extracting solvent. HTEAU process combines the use of two types of commercial equipments and technologies. The first is Ultra-turrax $^{\circledR}$ rotor-stator technology, which produces high turbulence in the plant material bed by high extracting solvent circulation flow rate (until $2000 \mathrm{~cm}^{3} / \mathrm{min}$ ) and the second is ultrasound technology, which is recognized to improve the extraction rate by the increasing the mass transfer and possible rupture of cell wall due the formation of microcavities. These equipments were coupled and put into operation at its maximum power of operability and the values for these parameters were determined through simultaneous optimization of oils, phenols, bixin recoveries. The effects of extraction method and solvent mass to feed mass ratio (S/F) on oils, phenols, bixin recoveries were evaluated by analyses of variance (ANOVA), demonstrating that the coupling of ultrasound probe into the Ultra-turrax ${ }^{\circledR}$ equipment statistically promotes the selective extraction of total phenols and bixin.
\end{abstract}

Keywords Ultra-turrax, Ultrasound, Active solution, Bixa orellana L, Bixin extraction

\section{Introduction}

A wide array of solid-liquid extraction techniques is widely used for the extraction of natural products from plant solid matrixes. Solid-liquid extraction techniques has been divided into traditional and recent method categories in [1,2]. Examples of traditional methods include maceration, leaching, and Soxhlet extraction. These techniques have been used for sometime; however, they are time-consuming and require large quantities of solvents. There is an increasing demand for new extraction techniques with shortened extraction time, reduced solvent consumption, and increased pollution prevention. Recent extraction methods such as Ultrasound Assisted Extraction (UAE), Microwave Assisted Extraction (MAE), Pressurized Liquid Extraction (PLE), Accelerated Solvent Extraction (ASE), and Supercritical Fluid Extraction (SFE) are fast and efficient for extracting chemicals from solid plant matrixes. These techniques have the possibility of working at elevated temperatures and/or pressures, greatly decreasing the time of extraction.

Annatto is obtained from the outer layer of the seeds of

* Corresponding author:

maameireles@gmail.com (M. Angela A. Meireles)

Published online at http://journal.sapub.org/fph

Copyright $@ 2015$ Scientific \& Academic Publishing. All Rights Reserved the tropical tree Bixa orellana $\mathrm{L}$. This tree is native to tropical South America; however, it is also cultivated in many countries in Central America (Mexico, Guatemala and Caribbean), Africa (Kenya, Tanzania, Côte d'Ivoire, Angola) and South Asia (India, Sri Lanka, Philippines, Vietnam). The main pigments of annatto seeds are bixin and norbixin, where bixin is the major pigment accounting for $80 \%$ of the total carotenoid content present contained in the resinous coating surrounding the seed itself. Its colour can vary in tone between yellow and red. Specifically, the major pigment present is cis-bixin; also present as minor constituents are trans-bixin, cis-norbixin and trans-norbixin.

The current work is motivated by the investigation of a 2 phase approach towards extracting, fractionating, and forming particles of cis-bixin derived from Annatto seeds. The first phase is focused on the efficient production of an active solution containing components of annatto using methods consistent with large-scale industrial food processing. The second phase is focused on the fractionation and particle formation of cis-bixin using Supercritical Antisolvent Fractionation. This paper will focus on the practical issues involved in the extraction methods used for the first phase in producing active solutions with the broad range of solid-liquid extraction methods in current use. In this study the High Turbulence Extraction Assisted by Ultrasound (HTEAU) device and procedures are described in detail and successfully developed using semi-defatted 
annatto seeds (Bixa orellana L.) as plant material and ethanol as extracting solvent as a model case.

\subsection{Overview of Extraction Methods}

The extraction of natural products from plants has likely existed since the time when humans first learned to created fire. Over the centuries, we have carried out solid-liquid extraction by brewing just about every common plant leaf, fruit, or root. In the process, we have extracted a number of compounds; many of them used for medicinal purposes.

More recently, surveys of traditional and "recent" methods for the extraction of natural products have been published [1,2]. The traditional methods cited typically include maceration [3], leaching [4-6], and Soxhlet extraction [7, 8]. More recent methods include Ultrasound Assisted Extraction (UAE) [9, 3, 10], Microwave Assisted Extraction (MAE) [3, 11], Pressurized Liquid Extraction [4, 12], Accelerated Solvent Extraction (ASE), Supercritical Fluid Extraction (SFE) [13], and certainly others can and will be devised. As suggested by Wang [1] all these forms of SLE may be generalized into a fundamental methodology of the extraction process.

In its fundamental form, the SLE process consists of a reservoir of fluid solvent in contact with a solid matrix containing solute(s). The process is then typically accelerated (with regard to processing time) or otherwise optimized (e.g. for yield) using various techniques. For instance, such techniques can be (1) pack the solid matrix within a solvent permeable membrane to facilitate or eliminate filtration of the final solution, (2) circulation, recirculation, or reflux of solvent to minimize the concentration of solute in direct contact with the solid matrix aiding mass transfer kinetics, (3) elevation of temperature to increase diffusion of solute and decrease the viscosity of the solution, (4) application of vacuum or pressure to tailor the extraction process through manipulation of the solvent phase state as used in SFE [13], (5) application of sonication to introduce cavitation formation and collapse processes at the solid matrix surface $[14,15,16]$ and (6) application of microwave fields to rapidly and uniformly heat polar/ionic solutions [17] and/or heat polar solutes within the solid matrix increasing intra-solid diffusion and potentially inducing cellular rupture within the solid matrix [18], however the process of superheating [19] must be considered when extracting natural products.

Therefore, the practical concerns for the ultimate extraction method and these techniques include the matrix characteristics and solid particle size, solvent choice, total solvent used and solid-liquid ratio, temperature and pressure, extraction time, solvent circulation, ultrasound power and frequency, and microwave power and frequency. These concerns are frequently addressed - and their parameters tailored - by experimental study using a design of experiments that statistically model the response of pertinent objectives against a factorized combination of the above items, as in $[4,10]$ for example. Investigations applying all these techniques simultaneously into a single experimental investigation are more recently appearing in the literature [20].

\subsection{Obtaining Active Compounds from Annatto Seeds}

Relevant methods and techniques used for the extraction of natural materials that have been published are gathered in the following. The sample of work reviewed encompasses the methods and techniques in the previous section and includes a number of studies related to the extraction of bixin from annatto.

Bixin was extracted from annatto seed in [6] (Table 1) by submerging the seeds in acetone and by combined extractions using sodium hydroxide and soybean oil in ambient daylight and dark conditions. The percent yield from leaching $5 \mathrm{~g}$ of seeds in $20 \mathrm{~cm}^{3}$ of acetone in daylight was $70.7 \%$ after $60 \mathrm{~min}$. The total bixin content within in the seeds was measured in determining the percent yield, but this total bixin content was not reported. However, assuming a typical bixin content of 1.0 to $4.9 \%,[4,10,8]$, the yield would be 18 to $35 \mathrm{~g} / \mathrm{kg}$.

The work in [8] studied the loss of bixin in annatto dye powder and annatto oleoresin in cold conditions in darkness, in darkness at room temperature, and room temperature in diffuse daylight. The annatto oleoresin was produced with $800 \mathrm{mg}$ annatto seeds having $1.68 \%$ bixin content using a Soxhlet extractor with acetone over 8 hours. The resulting extracted product was reported as yielding $11.60 \mathrm{~g}$ bixin per $100 \mathrm{~g}$ extracted product (equivalent to $11.60 \mathrm{mg}$ bixin per $100 \mathrm{mg}$ of extracted product). It is noted however that it is assumed here that the total extracted bixin is $11.60 \mathrm{~g}$.

Bixin was also the targeted extracted solute by Rodrigues et al. [4]. Two methods termed Pressurized Liquid Extraction (PLE) and Low Pressure Solvent Extraction (LPSE) were studied. A full factorial design of experiments was performed for both methods over temperature, pressure, solvent to feed ratio, with and without sonication with both continuously and pulsed application, and solvent type. Ultimately, the LPSE method was selected for detailed investigation, including Scanning Electron Microscope (SEM) imaging to study the resulting surface morphology. The extraction time was $85 \mathrm{~min}$ with a resulting yield of 4 $\mathrm{g} / \mathrm{kg}$ at $323 \mathrm{~K}$ and $6 \mathrm{~g} / \mathrm{kg}$ at $333 \mathrm{~K}$. It was noted that both the application of increased pressure in PLE and sonication in LPSE did not significantly improve the extraction process.

An evaluation between PLE and LPSE was also conducted in [12] using ethanol, ethyl acetate, and water as solvents for the extraction of bixin from annatto seeds. The largest yield of bixin per mass of seeds was achieved with PLE with ethanol as the solvent. The results indicated that water is not recommended as a suitable solvent for PLE extraction of bixin from annatto. However, it is noted that water was the best performing for LPSE with water (about $3.3 \%$ more than for PLE), with the extractions carried out using agitation. Therefore, the use of ethanol for extraction of bixin is a viable alternative, since it could be easily separated from the 
extract, which would represent a lower energy expenditure in its obtaining.

Supercritical fluid extraction of bixin was studied using $\mathrm{CO}_{2}$ and $\mathrm{CO}_{2}$ modified with $5 \mathrm{~mol} \%$ of ethanol as solvents by Nobre et al. [13]. The extraction efficiency using the modified $\mathrm{CO}_{2}$ was significantly improved. It was noted that different conditions over temperature and solvent flow rate were carried out.

Bixin was extracted from annatto seeds in a spouted bed using ambient air as the fluid [21]. Mechanical attrition of the seed's pigment layer produced dry powder with $44.3 \%$ bixin content; an extraction time of 4 hours yielded $34.76 \mathrm{~g}$ bixin per $\mathrm{kg}$ of annatto seeds (equivalent to $3.48 \mathrm{mg}$ bixin per $100 \mathrm{mg}$ of annatto seeds). The study didn't provide data on the percent bixin content within the seeds used, however assuming a typical range of 1.0 to $4.9 \%[4,10,8]$ it appears that this technique extracted 71 to $100 \%$ of the bixin content of the annatto seed in powder form.

A study was conducted [10] for the simultaneous extraction of bixin and phenols using UAE over a range of extraction parameters including ratio of methanol: water $(8: 2$ $\mathrm{v} / \mathrm{v}$ ) to acetone solution, solid to liquid ratios from 1:1 to $1: 9$ $\left(\mathrm{g} / \mathrm{cm}^{3}\right)$, extraction time from 5 to $25 \mathrm{~min}$, and number of extractions from 5 to 25 . After determining, the optimum condition of the simultaneous extract a yield of $11.1 \mathrm{~g} / \mathrm{kg}$ of bixin and $1.9 \mathrm{mg} / \mathrm{g}$ phenols was achieved for fifteen (15) 5 min extractions.

In a study using organic dyes for use in solar cell technology [5], bixin was extracted by immersing $20 \mathrm{~g}$ of seeds in $200 \mathrm{~cm}^{3}$ of ethyl acetate in an Erlenmeyer flask and sonicated for $1 \mathrm{hr}$ in an ultrasonic bath at a temperature below $333 \mathrm{~K}$. The solution was subsequently concentrated and fractionated producing $0.42 \mathrm{~g}$ of bixin, resulting in a yield of $2.1 \mathrm{~g} / \mathrm{kg}$. It is noted that the ultrasonic power and frequency applied was not reported. The total bixin content in the seeds used was also not reported, but assuming 1.0 to $4.9 \%$ [4] the percent yield was estimated to range from 4 to $8 \%$.

On the other hand, to date it has been reported in the scientific literature that units at laboratory scale such as the ultra-turrax and ultrasound have been used separately for various purposes. For that, High Turbulence Extraction (HTE), process developed with ultra-turrax equipment, is produced by the high extracting solvent circulation flow rate (until $2000 \mathrm{~cm}^{3} / \mathrm{min}$ ) produced thanks to the gap between the rotor and stator [22]. On the other hand. the application of ultrasonic energy causes the rupture of cells (UAE), bony, the transfer of high power electrical energy into mechanical energy through the transducer, introduces the ultrasonic pressure waves forming cycles of tension and compression inside the liquid [23]. The present work shows the coupling of these two units, as a new proposal of technique (named by High Turbulence Extraction Assisted by Ultrasound, HTEAU) for the extraction of active compounds from the semi-defatted annatto seeds, with the goal of increasing the presence of a specific compound (bixin, in such case) in the active solutions (AS). It should be noticed that the active solution produced could be further processed to become a dry extract by conventional drying processes.

\section{Materials and methods}

\subsection{Plant Material Preparation}

Table 1. Obtaining of bixin-rich extract using different extraction methods from annatto seeds

\begin{tabular}{|c|c|c|c|c|c|c|}
\hline Reference & {$[6]$} & [8] & [13] & {$[21]$} & {$[10]$} & {$[5]$} \\
\hline Bixin in Solid Matrix (\%) & N/A & 1.69 & 0.80 & N/A & 1.41 & N/A \\
\hline Extraction Method & Leaching & Soxhlet & SFE & Spouted Bed & UAE & UAE \\
\hline \multirow[b]{2}{*}{ Extracting Solvent } & \multirow[b]{2}{*}{ acetone } & \multirow[b]{2}{*}{ acetone } & $\mathrm{CO}_{2}$ & & \multirow[b]{2}{*}{$\begin{array}{l}\text { Mixture of methanol, } \\
\text { water and acetone }\end{array}$} & \multirow[b]{2}{*}{ ethyl acetate } \\
\hline & & & $\begin{array}{c}\mathrm{CO}_{2}: 5 \% \text { mol } \\
\text { ethanol }\end{array}$ & Air & & \\
\hline \multirow{2}{*}{$\begin{array}{c}\text { S/F (g extracting } \\
\text { solvent/g raw material) }\end{array}$} & \multirow{2}{*}{3.1} & \multirow{2}{*}{1} & 9.2 & \multirow{2}{*}{191} & \multirow{2}{*}{7.3} & \multirow{2}{*}{9} \\
\hline & & & 9.5 & & & \\
\hline $\begin{array}{c}\text { Extracting Solvent } \\
\text { Circulation }\left(\mathrm{cm}^{3} / \mathrm{min}\right)\end{array}$ & --- & N/A & 340 & 1661666.7 & 1.83 & --- \\
\hline Temperature (K) & 323 & N/A & 313 & ambient & 298 & $<333$ \\
\hline Pressure (bar) & ambient & ambient & 200 & ambient & ambient & ambient \\
\hline Extraction Time (min) & 60 & 480 & 50 & 240 & 75 & 60 \\
\hline
\end{tabular}


Annatto seeds, Red Piave variety (crop 2013) of the Station of the Grains Ltda. (São Paulo, Brazil) was used in the experiments. The defatting process was carried out in a pilot scale supercritical fluid extraction equipment (Thar Technologies, SFE- $2 \times 5$ LF-2FMC, Pittsburgh, USA). The oil removal with supercritical carbon dioxide as the solvent (99.9\% $\mathrm{CO}_{2}$, Gama Gases Especiais Ltda., São Bernardo do Campo, Brazil) had the following conditions: $\mathrm{T}=313 \mathrm{~K}, \mathrm{P}=$ $200 \mathrm{bar}$, flow of $\mathrm{CO}_{2}=200 \mathrm{~g} / \mathrm{min}$ and solvent mass to feed mass ratio $(\mathrm{S} / \mathrm{F})=11$. The value of $\mathrm{S} / \mathrm{F}$ was $68.6 \%$ lower than that used by Albuquerque and Meireles [24], and with it the seeds had the final condition of semi-defatted. The semi-defatted annatto seeds were stored in freezer (Metalfrio, model DA420, São Paulo, Brazil) at $263 \mathrm{~K}$.

\subsection{Chemical Characterization of Semi-Defatted Annatto Seeds and Active Solutions (AS)}

The determination of the chemical composition of the semi-defatted annatto seeds was performed at LAPEA/DEA/ UNICAMP (oil content) and at LASEFI/DEA/UNICAMP (total phenols and bixin contents).

\subsubsection{Oil Content Determination}

The oil content of the semi-defatted annatto seeds was performed by the AOCS Official Method Ba 3-38 [25], before and after obtaining the AS. It was used an analytical balance (Sartorius analytic A200S, $\pm 0.0001 \mathrm{~g}$, Sartorius GMBH Göttingen, Germany) for to weigh approximately $5 \mathrm{~g}$ of semi-defatted annatto seeds. Petroleum ether (Chemco, lot 29402, Sinergia, Campinas, Brazil) was used as an extracting solvent in the Soxhlet apparatus. A rotary evaporator (Heildoph Instruments, model 4001 Laborota, Viertrieb, Germany) vacuum was used for evaporation of the extracting solvent. The determination of the oil content was performed in two repetitions.

The determination of the total phenols and bixin contents from the semi-defatted annatto seeds (before obtaining the AS) and of the AS were also performed as described below.

\subsubsection{Total phenols Content Determination}

For the determination of total phenols content of the seeds and AS were determined by Folin-Ciocalteu method [26], with some adaptations to plant extracts suggested by Singleton et al. [27]. Total phenols was extracted for characterization of the raw material from the semi-defatted annatto seeds with hydroethanolic solvent (ethanol:water $10: 90 \mathrm{v} / \mathrm{v}$ ) by vortex agitation to enhance the efficiency of extraction during $5-8 \mathrm{~min}$. The obtained dry extracts by active solution solvent removal were diluted in hydroethanolic solvent (ethanol:water 10:90 v/v) to the concentrations appropriate for analysis. It was used $20 \mathrm{mg}$ of dry extract (product from AS after evaporation of the extracting solvent) with an analytical balance (Sartorius Analytic A200S, $\pm 0.0001 \mathrm{~g}$, Sartorius GMBH Göttingen, Germany). Gallic acid (Sigma-Aldrich, lot 023K 01171, USA), ethanol (Chemco, lot 26894, Sinergia, Campinas,
Brazil) and distilled water were used to prepare the calibration solutions.

The absorbance was read at UV-vis spectrophotometer (Hitachi, model U-3010, Tokyo, Japan) using measurement of $760 \mathrm{~nm}$ wavelength. For the purpose of this determination, the absorbance readings were done in three replicates.

\subsubsection{Bixin Content Determination}

The bixin content of the seeds and AS were determined according to the set of monographs FAO/WHO experts Committee on food additives [28] and adapted by Albuquerque and Meireles [24]. Both the spectrophotometer and analytical balance were the same used in the determination of total phenolic content. The obtained dry extracts by active solution solvent removal were diluted in acetone to the concentrations appropriate for analysis. Thus, it was weighed approximately $1 \mathrm{mg}$ of dry extracts (product from AS after evaporation of the extracting solvent). The absorbance was read in three replicates, at measure $487 \mathrm{~nm}$ wavelength. The bixin content of the seeds and AS was calculated in accordance with the law of Lambert-Beer, using the coefficient estimate [24]:

$$
E_{1 \mathrm{~cm}}^{1 \%}=3090
$$

\subsection{Process Description}

Two main pieces were coupled to shape the novel selective extraction method to produce the active solutions. A schematic diagram of the coupling of the equipments used to obtain the AS can be seen in Figure 1. The first (drawn in blue color) is from IKA using their Ultra-turrax ${ }^{\circledR}$ (Dijkstra Vereenigde, IKA ${ }^{\circledR}$ magic LAB ${ }^{\circledR}$, NJ Lelystad, Holland) rotor-stator technology and the second (drawn in gray color) is an ultrasonic mixing system from Unique Group (Desruptor, Indaiatuba, Brazil). It should be consider that in the present work it is the first time the Ultra-turrax has been used for the extraction of AS from any plant material.

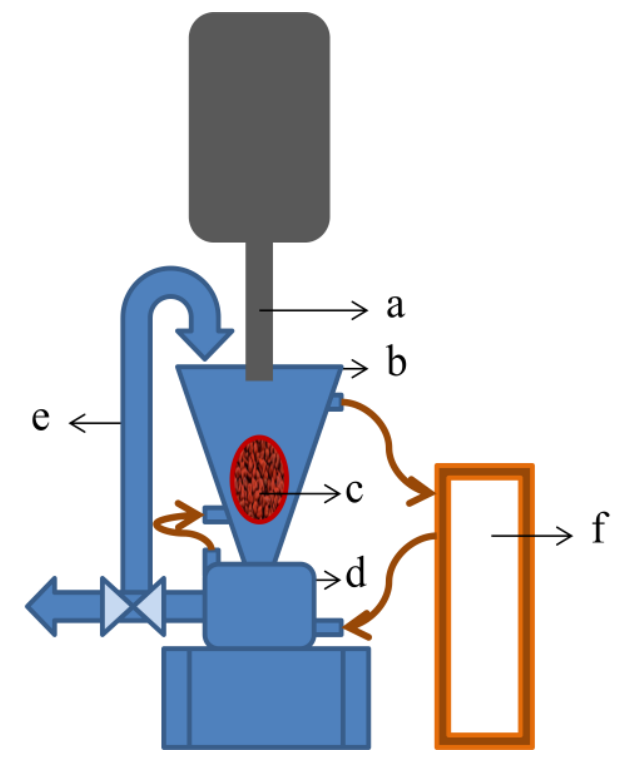

Figure 1. Novel selective extraction method to produce AS 
The Ultra-turrax equipment in this study is typically used for the production of emulsions and suspensions. According to Figure 1, the letters b, $d$ and e, represent a funnel (vessel 1 L), a basic unit with module ULT (in whose interior finds the rotor-stator technology) and a circulation pipe (allows for AS recirculation), respectively. The unit was operated at its maximum speed (the high rotation speed of the rotor) of 26,000 rpm, which produces a extracting solvent circulation flow rate of $2000 \mathrm{~cm}^{3} / \mathrm{min}$. The ultrasound equipment consists of a control unit, a probe (letter a) and an ultrasonic transducer. For the work the ultrasonic power was set to its maximum $800 \mathrm{~W}$. Additionally, there are 2 probes that may be selected, a micro and a macro, and the macro sized probe was used. The letters $\mathrm{c}$ and $\mathrm{f}$, represent, a polyester bag that contained the semi-defatted annatto seeds and thermostatic bath (Marconi, model MA184, Brazil), respectively.

The High Turbulence Extraction (HTE) and High Turbulence Extraction Assisted by Ultrasound (HTEAU) processes were conducted using the equipment seen in Figure 1. During HTEAU process, the ultrasound probe was submerged $3 \mathrm{~cm}$ into the solution within the Ultra-turrax funnel.

First, the semi-defatted annatto seeds placed into a polyester bag with 150 threads per $\mathrm{cm}^{2}$ (Silk Screen Brazil, Prairies, Brazil) were weighed with an analytical balance (Sartorius Analytic A200S, \pm 0.0001 g, Sartorius GMBH Göttingen, Germany). Then the require mass of ethanol was brought to $333 \mathrm{~K}$ in a bath (Marconi, model MA184, Brazil). The bags of semi-defatted annatto seeds and solvent were then fed into of Ultra-turrax funnel. The ultrasound probe was installed, if used, and the extraction was conducted for $40 \mathrm{~min}$, while maintaining the solution at $333 \mathrm{~K}$. At the end of the 40 min duration, the AS was cooled. The HTE was conducted without ultrasound applied. Ethanol (Synth, lot 180675, Diadema, São Paulo, Brazil) was used as extracting solvent, and it's quantity was studied over solvent to feed ratios $(\mathrm{S} / \mathrm{F})$ of $1.6,3.9$, and $7.8(\mathrm{mg} / \mathrm{mg})$.

The total volume of AS collected $\left(A S_{t v}\right)$ from the funnel was recorded. The procedure for determining the solids content of the AS was the following: the mass of the empty petri plate was registered (initial mass $\left(m_{I}\right)$ ) and then a volume of $10 \mathrm{~cm}^{3}$ of $\mathrm{AS}(A S v)$ was placed inside the petri plate (optionally the mass of the AS to the interior of the petri plate was registered), this petri plate was transferred within a fume cupboard to evaporate the ethanol at room temperature and get a weight constant mass (final mass $\left(m_{F}\right)$ ). The solids content $(S c)$ was calculated through the subtraction between the final mass less the initial mass, the result of this subtraction was divided by the volume of $10 \mathrm{~cm}^{3}$ (solid mass/AS volume), according to Equation 2. This procedure was performed in four replicates (Equation 3.1 or 3.2).

$$
S c=\frac{m_{F}-m_{I}}{A S v}
$$

$$
\begin{gathered}
S c_{4}=\sum_{i=1}^{l=4}\left[\frac{m_{F}-m_{I}}{A S v}\right]_{i} \\
S c_{4}=\frac{\left(m_{F}-m_{I}\right)_{i}+\left(m_{F}-m_{I}\right)_{j}+\left(m_{F}-m_{I}\right)_{k}+\left(m_{F}-m_{I}\right)_{l}}{A S v_{i}+A S v_{j}+A S v_{k}+A S v_{l}}
\end{gathered}
$$

The total mass of the collected extract $\left(m_{\text {extract }}\right)$ is then determined by multiplying the total volume of AS obtained from the extraction process with the solids content of the AS determined above (Equation 4). The overall extraction yield $\left(X_{0} \%\right)$ is then the ratio of $m_{\text {extract }}$ to the mass of the raw material $\left(m_{\text {sample }}\right)$ processed, multiplied by 100 (Equation 5$)$.

$$
\begin{gathered}
X_{0} \%=\frac{m_{\text {extract }}}{m_{\text {sample }}} \times 100 \\
m_{\text {extract }}=S c_{4} \times A S_{t v}
\end{gathered}
$$

\subsection{Experimental Design and Statistical Analysis}

To validate the novel extraction method to produce AS using semi-defatted annatto seeds as a model plant material and ethanol as extracting solvent, as well as was also prepared the Table 2, according to the following criteria, it was analyzed the technical limitation of the coupling of the units, both the Ultra-turrax and ultrasound. Thus, it was decided to consider the development of extractions with solvent mass to feed mass ratio $(\mathrm{S} / \mathrm{F})=$ ethanol mass/raw material mass at minimum, intermediate and maximum values. Taking into consideration that the ultrasound probe is immersed in solvent $3 \mathrm{~cm}$ and at the same time is free of contact with polyester bag that contains the semi-defatted annatto seeds.

In this way, were defined the values of $\mathrm{S} / \mathrm{F}$ minimum, intermediate and maximum, 1.6, 3.9 and 7.8, respectively. At the same time, were devised two different methods. Named in the present study as HTE and HTEAU, when ultrasound is off and running, respectively. Already with this information, it was decided to make two extractions for each combination,

\begin{tabular}{|c|c|c|c|}
\hline $\mathrm{S} / \mathrm{F}$ & $\begin{array}{c}\text { Extraction } \\
\text { method }\end{array}$ & Ultra-turrax & Ultrasound \\
\hline 1.6 & HTE & \multirow{6}{*}{$\begin{array}{c}900 \mathrm{Watts} \\
26000 \mathrm{rpm} \\
2000 \mathrm{~cm}^{3} / \mathrm{min} \\
\text { Temperature } 333 \mathrm{~K} \\
\text { Time }=40 \mathrm{~min}\end{array}$} & \multirow{6}{*}{$\begin{array}{c}800 \text { Watts } \\
19 \mathrm{kHz} \\
\text { Temperature } 333 \mathrm{~K} \\
\text { Time }=40 \mathrm{~min}\end{array}$} \\
\hline 1.6 & HTEAU & & \\
\hline 3.9 & HTE & & \\
\hline 3.9 & HTEAU & & \\
\hline 7.8 & HTE & & \\
\hline 7.8 & HTEAU & & \\
\hline
\end{tabular}
totalling 12 experiments. In addition, the values for these parameters were determined through simultaneous optimization of oils, phenols and bixin recoveries.

Table 2. Extraction conditions for obtaining AS 
In addition to the statistical analysis it was used Minitab ${ }^{\circledR}$ v. 16 software to determine the effects of extraction method and solvent mass to feed mass ratio $(\mathrm{S} / \mathrm{F})$ on oils, phenols, bixin recoveries with a confidence interval of $95 \%$ ( $p_{\text {value }} \leq$ $0.05)$. Statistical analyses were performed using analyses of variance (ANOVA).

\section{Results and Discussion}

\subsection{Chemical Characterization of Semi-defatted Annatto Seeds and Active Solutions (AS)}

The determination of total phenols and bixin content in the active solutions to the quotient of solvent mass to feed mass ratio $(\mathrm{S} / \mathrm{F}) 7.8$, was rejected due to projected future uses of this solution. For example, for the extraction processes with organic solvents, which interest is to obtain a high concentration of solid inside the extracted product, a low or intermediate quotient of $\mathrm{S} / \mathrm{F}$ is wished. In the opposite case, it will have to assume the additional costs to which it bears later another necessary process to concentrate the product extracted through evaporation processes.

The content of oils of the semi-defatted annatto seeds before obtaining the AS was $1.24 \%$ (wet basis, w.b.). The HTEAU, appears selective in the retention of oils in the seeds (Figure 2a), this selectivity is still more notorious when a ratio $\mathrm{S} / \mathrm{F}$ is used to 1.6 . So, the quantity of oils kept in the seeds was of approximately $40 \%$, whereas for S/F 7.8 of HTE the quantity of oils kept in the seeds was approximately $9 \%$, the error bars represent the amplitude.

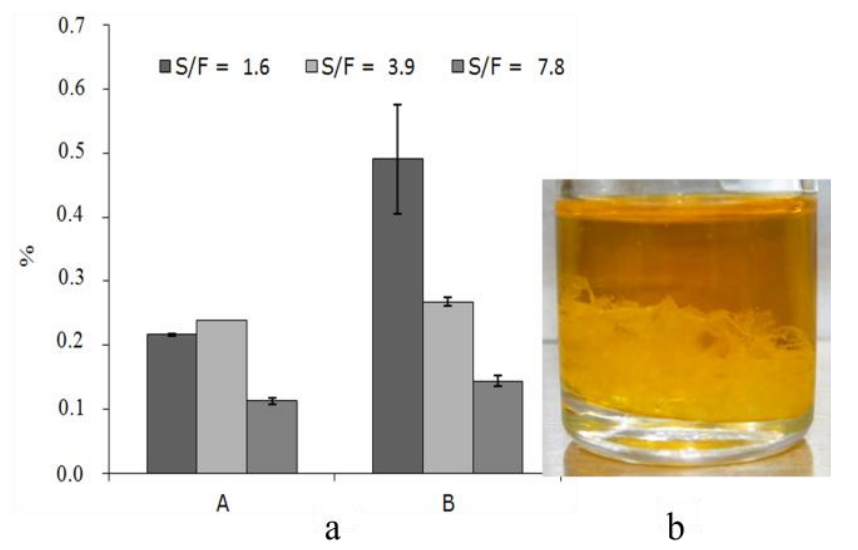

Figure 2. a) Oil content in seeds $(\%, g / 100 \mathrm{~g}$ seed oil on wet base) after extraction to obtain AS where A $=$ HTE and B = HTEAU, b) Appearance of the oil after removal by the Soxhlet method

Looking at Figure $2 b$, we can infer that the HTEAU facilitates the drag of starch of the interior of the semi-defatted annatto seeds for outside, the presence of starch generates chemical bonds with the oils, forming molecular structures of larger size. In consequence, the step of them news molecular structures for outside across the baskets of nylon is less and they are retained in the internal walls of baskets that are in contact with the semi-defatted annatto seeds. At the same time, the presence of lower amount of ethanol in these conditions of extraction contributes with that broadcast from the interior of the basket toward whichever is less.

For the case of the total phenols content of samples was calculated in Gallic acid equivalents (GAE). The determination of the content of total phenols in AS (Figure 3) was approximately $0.67 \mathrm{mg}$ GAE/100 mg AS extract and $0.75 \mathrm{mg}$ GAE/100 mg AS extract when used S/F 1.6, in HTE and HTEAU, respectively. For S/F 3.9 this content of total phenols was approximately $0.79 \mathrm{mg}$ GAE/100 mg AS extract and $0.93 \mathrm{mg} \mathrm{GAE} / 100 \mathrm{mg}$ AS extract, in HTE and HTEAU, respectively.

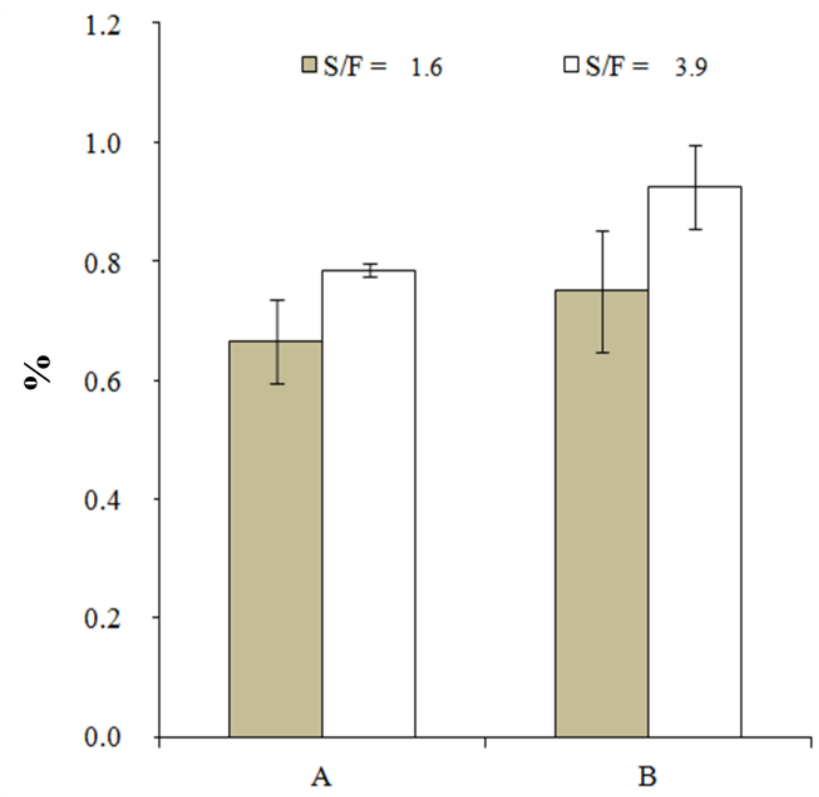

Figure 3. Extraction efficiency of total phenols content from AS extracts, where $\mathrm{A}=\mathrm{HTE}$ and $\mathrm{B}=\mathrm{HTEAU}(\%, \mathrm{mg}$ GAE$/ 100 \mathrm{mg}$ of extract)

The total phenols content for the semi-defatted annatto seeds extract (w.b.) was $1.65 \mathrm{mg}$ GAE/100 mg (\%). Our results demonstrate that approximately $40-55 \%$ of the initial phenolic compounds are recovery by the proposed processes.

Already in the case of the extraction efficiency of bixin, represent $4 \%$ and approximately $7 \%$ to S/F 1.6, for HTE and HTEAU, respectively. For S/F 3.9, for HTE and HTEAU, represent approximately 9 and $12 \%$, respectively.

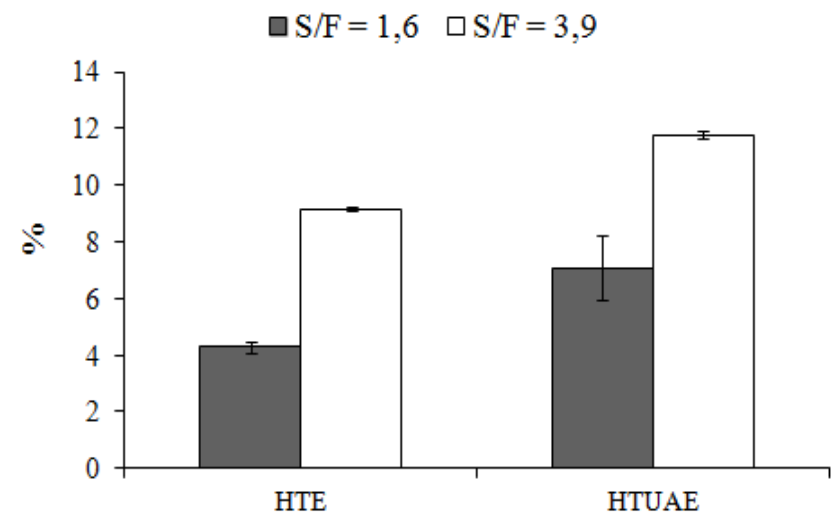

Figure 4. Extraction efficiency of bixin from AS extracts, where A = HTE and $\mathrm{B}=\operatorname{HTEAU}(\%, \mathrm{mg}$ bixin/100 $\mathrm{mg}$ of extract $)$ 


\subsection{Effects of the Extraction Method and Solvent Mass to Feed Mass Ratio (S/F)}

The coupling of ultrasound probe of ultra-turrax equipment as a novel extraction method to produce AS, proved to be selective with regard to obtaining bixin and phenolic and oil retention in the seed semi-degreased. This selectivity is confirmed through the analysis of variance (ANOVA) observed in Table 3.

As well, in the Table 3 for the oil content in the remaining seeds the effects of $\mathrm{S} / \mathrm{F}$ ( $\left.p_{\text {value }}<0.0005\right)$, extraction method $\left(p_{\text {value }}<0.0005\right)$ and the interaction of these $\left(p_{\text {value }}=0.001\right)$ were statistically significant.

Figure 3 shows that the percentage of total phenols in AS has increased. Being significant the effects of $\mathrm{S} / \mathrm{F}$ ( $p_{\text {value }}=$ $0.014)$ and extraction method $\left(p_{\text {value }}=0.034\right)$; however, the interaction of these effects was not significant $\left(p_{\text {value }}=0.477\right)$ according to Table 3.

The biggest ratio $\mathrm{S} / \mathrm{F}$ and the HTEAU method increased the content of total phenols and bixin in AS. This increase was significant for the ratio $\mathrm{S} / \mathrm{F}\left(p_{\text {value }}<0.0005\right)$ and to extraction method $\left(p_{\text {value }}=0.007\right)$ for bixin content in AS.

\subsection{Literature Comparision}

Thus, Table 4 shows a comparison between bixin extraction eficiencies of those researches with the results obtained in this research. When compared the results of extraction efficiency of bixin of this research with literature information using the same extracting solvent and different extraction methods, it can be seen that our proposed process is very promising Therefore, it should be noticed that the content of oil in the extracts is also high and that extraction efficiency is a function of time.

On the other hand, it is observed that in all cases with the exception of the paper by Nobre et al. [13], that used supercritical $\mathrm{CO}_{2}$, the type of solvent used in the various methods of extraction is regarded as non-secure, so it's not completely accepted for use in food products. In this sense, the present study also is the first research which uses whole seeds of annatto in its condition of semi-defatted, generating to some extent intermediate results by initial characteristics physical-chemical starters in this new process of extraction (HTEAU), in contrast to studies conducted by Rodrigues et
[4] and Rodrigues et al. [12], whose research used completely defatted seeds and also used ethanol as extracting solvent and a Low Pressure Solvent Extraction (LPSE) equipment with ultrasound assistance (LPSE-UAE).

It should be noticed that the value of $S / F$ used for oil removal from annatto seeds in our study was approximately $68.6 \%$ lower than those values of S/F used to completely defatte the seeds through the supercritical fluid extraction pilot unit. Therefore, these first results for the extraction of bixin as main compounds of annatto seeds were possibly also affected by the presence of other compounds extracted along with the bixin, which interfere with the moment to quantify the content of bixin in the spectrophotometer. Some small changes in the configuration of the packaging of the seeds before placing to the inside of the vessel of the Ultra-turrax might increase the performance of extraction. This means, the textile used in the making of bags for packing the semi-degreased annatto seeds must contain a lesser amount of threads per $\mathrm{cm}^{2}$ to facilitate greater mass transfer from the inside to outside of the packaging. Remember that in section 2.3, was mentioned that the textile used for the making of bags contained 150 threads per $\mathrm{cm}^{2}$. An alternative proposal could be, for example, use nylon textile with 80 threads per $\mathrm{cm}^{2}$. Thus, further experiments will be done in such direction.

\section{Conclusions}

A hybrid technique coupling an Ultra-turrax ${ }^{\circledR}$ rotor-stator technology and an ultrasonic mixing system was successfully developed. Named by High Turbulence Extraction Assisted by Ultrasound (HTEAU) this novel process was described in detail using semi-defatted annatto seeds (Bixa orellana L.) as plant material and ethanol as extracting solvent as a model case. Additionally, the effects of extraction method and solvent mass to feed mass ratio (S/F) on oils, phenols and bixin recoveries were evaluated by analyses of variance (ANOVA). The biggest ratio S/F and the HTEAU method increased the content of total phenols and bixin in AS. Further experiments will be done using different raw materials in order to confirm the observed improvements by the coupling of both equipments.

Table 3. Analyses of variance (ANOVA) for the extraction

\begin{tabular}{cccccccccc}
\hline \multirow{2}{*}{ Source } & \multicolumn{3}{c}{ Oils } & \multicolumn{4}{c}{ Total phenols } & \multicolumn{3}{c}{ Bixin } \\
\cline { 2 - 10 } & DF & Seq SS & $\mathbf{p}_{\text {value }}$ & DF & Seq SS & $\mathbf{p}_{\text {value }}$ & DF & Seq SS & pvalue \\
\hline S/F & 2 & 0.101818 & 0.000 & 1 & 0.0000044 & 0.014 & 1 & 0.000056 & 0.000 \\
\hline Extraction method & 1 & 0.037568 & 0.000 & 1 & 0.0000025 & 0.034 & 1 & 0.0000012 & 0.007 \\
\hline $\begin{array}{c}\text { S/F* Extraction } \\
\text { method }\end{array}$ & 2 & 0.039728 & 0.001 & 1 & 0.0000002 & 0.477 & 1 & 0.000000 & 0.877 \\
\hline Error & 6 & 0.003671 & & 4 & 0.0000010 & & 4 & 0.0000002 & \\
\hline Total & 11 & 0.182785 & & 7 & 0.0000080 & & 7 & 0.0000070 & \\
\hline
\end{tabular}


Table 4. Bixin extraction eficiencies from whole semi-defatted annatto seeds using ethanol as extracting solvent

\begin{tabular}{|c|c|c|c|}
\hline Extraction method & $\mathrm{S} / \mathrm{F}$ & $\begin{array}{c}\text { Bixin extraction } \\
\text { eficiency }(\%)(\mathrm{mg} \\
\text { bixin/100 mg of extract) }\end{array}$ & Reference \\
\hline \multirow{2}{*}{ LPSE-UAE } & 4 & $1.41-7.42$ & \multirow{4}{*}[4]{} \\
\hline & 8 & $3.54-7.58$ & \\
\hline \multirow{2}{*}{ PLE } & 4 & $1.84-6.08$ & \\
\hline & 8 & $2.15-4.48$ & \\
\hline \multirow{3}{*}{ HTE } & 1.6 & 4 & \multirow{6}{*}{$\begin{array}{l}\text { In this } \\
\text { research } \\
\text { study }\end{array}$} \\
\hline & 3.9 & 9 & \\
\hline & 7.8 & --- & \\
\hline \multirow{3}{*}{ HTEAU } & 1.6 & 7 & \\
\hline & 3.9 & 12 & \\
\hline & 7.8 & --- & \\
\hline
\end{tabular}

\section{ACKNOWLEDGEMENTS}

The authors are grateful to FAPESP (2012/10685-8) for financial support. R. Abel C. Torres thanks CNPq (190424/2012-5) for a MSc. assistantship and Rosa Koretzky for the translation of this article. Diego T. Santos thanks FAPESP (10/16485-5) and CAPES for the postdoctoral fellowships. M. A. A. Meireles thanks CNPq for a productivity grant (301301/2010-7).

\section{REFERENCES}

[1] L. Wang, C. L. Weller, "Recent advances in extraction of nutraceuticals from plants", Trends in Food Science \& Technology, vol.17, no.6, pp.300-312, 2006.

[2] B. Kaufmann, P. Christen, "Recent Extraction Techniques for Natural Products: Microwave-assisted Extraction and Pressurised Solvent Extraction", Phytochemical Analysis, vol.13, pp.8, 2002.

[3] L. Alexandru, A. Binello, S. Mantegna, L. Boffa, F. Chemat, G. Cravotto, "Efficient green extraction of polyphenols from post-harvested agro-industry vegetal sources in Piedmont", Comptes Rendus Chimie, vol.17, no.3, pp.212-217, 2014.

[4] L. M. Rodrigues, S. C. Alcázar-Alay, A. J. Petenate, M. A. A. Meireles, "Bixin extraction from defatted annatto seeds", Comptes Rendus Chimie, vol.17, no.3, pp.268-283, 2014.

[5] N. M. Gómez-Ortíz, I. A. Vázquez-Maldonado, A. R. Pérez-Espadas, G. J. Mena-Rejón, J. A. Azamar-Barrios, G. Oskam, "Dye-sensitized solar cells with natural dyes extracted from achiote seeds", Solar Energy Materials and Solar Cells, vol.94, no.1, pp.40-44, 2010.

[6] H. Van Chuyen, N. T. N. Hoi, J. B. Eun, "Improvement of bixin extraction yield and extraction quality from annatto seed by modification and combination of different extraction methods", International Journal of Food Science and Technology, vol.47, no.7, pp.1333-1338, 2012.

[7] Y. Li, F. Fine, A.-S. Fabiano-Tixier, M. Abert-Vian, P. Carre,
X. Pages, F. Chemat, "Evaluation of alternative solvents for improvement of oil extraction from rapeseeds", Comptes Rendus Chimie, vol.17, no.3, pp.242-251, 2014.

[8] K. Balaswamy, P. G. Prabhakara Rao, A. Satyanarayana, D. G. Rao, "Stability of bixin in annatto oleoresin and dye powder during storage", LWT - Food Science and Technology, vol.39, no.8, pp.952-956, 2006.

[9] P. G. Prabhakara Rao, T. Jyothirmayi, K. Balaswamy, A. Satyanarayana, D. G. Rao, "Effect of processing conditions on the stability of annatto (Bixa orellana L.) dye incorporated into some foods", LWT - Food Science and Technology, vol.38, no.7, pp.779-784, 2005.

[10] R. C. Chisté, F. Yamashita, F. C. Gozzo, A. Z. Mercadante, "Simultaneous extraction and analysis by high performance liquid chromatography coupled to diode array and mass spectrometric detectors of bixin and phenolic compounds from annatto seeds", Journal of Chromatography A, vol.1218, no.1, pp.57-63, 2011.

[11] V. Soumya, P. Venkatesh, P. K. Hari, B. Shrishailappa, "Microwave facilitated extraction of Bixin from Bixa orellana and it's in-vitro antioxidant activity", http://scholarsresearchl ibrary.com/archive.html, Scholars Research Library, vol.2, no.2, 2010.

[12] L. M. Rodrigues, S. C. Alcázar-Alay, M. T. M. S. Gomes, M. A. A. Meireles, "Pressurized liquid extration (PLE) of bixin from defatted Annatto seeds", in III Iberoamerican Conference on Supercritical Fluids, 2013.

[13] B. P. Nobre, F. L. P. Pessoa, J. P. Coelho, A. F. Palavra, R. L. Mendes, "Supercritical carbon dioxide extraction of bixin from annatto seeds", International Society for Advancement of Supercritical Fluids, pp.6, 1999.

[14] A. Lawrence, "Cavitation in Ultrasonic Cleaning and Cell Disruption", Controlled Environments, pp.4, 2009.

[15] K. S. Suslick, "The chemical effects of ultrasound", Scientific American Magazine, 1989.

[16] S. Verdan, G. Burato, M. Comet, L. Reinert, H. Fuzellier, "Structural changes of metallic surfaces induced by ultrasound", Ultrasonics Sonochemistry, vol.10, no.4-5, pp.291-295, 2003.

[17] C. O. Kappe, D. Dallinger, "The impact of microwave synthesis on drug discovery", Nat Rev Drug Discov, vol.5, no.1, pp.51-63, 2006.

[18] G. Brodie, M. V. Jacob, M. Sheehan, L. Yin, M. Cushion, G. Harris, "Microwave modification of sugar cane to enhance juice extraction during milling", Proceedings of the Australian Society of Sugar Cane Technology, vol.33, pp.8, 2011.

[19] D. R. Baghurst, D. M. P. Mingos, "Superheating Effects Associated with Microwave Dielectric Heating", Cheminform, vol.23, no.39, pp.316-316, 1992.

[20] G. Cravotto, L. Boffa, S. Mantegna, P. Perego, M. Avogadro, P. Cintas, "Improved extraction of vegetable oils under high-intensity ultrasound and/or microwaves", Ultrasonics Sonochemistry, vol.15, no.5, pp.898-902, 2008.

[21] F. G. Cunha, K. G. Santos, C. H. Ataíde, N. Epstein, M. A. S. Barrozo, "Annatto powder production in a spouted bed: An experimental and CFD study", Industrial and Engineering 
Chemistry Research, vol.48, no.2, pp.976-982, 2009.

[22] Online Available: http://www.ika.com.my/PDF/201007_Pilo ts_EN_IWK_USD_spreads_screen.pdf.

[23] Online Available: http://www.unique.ind.br/desruptor.html\# desruptor.html.

[24] C. L. C. Albuquerque, M. A. A. Meireles, "Defatting of annatto seeds using supercritical carbon dioxide as a pretreatment for the production of bixin: Experimental, modeling and economic evaluation of the process", Journal of Supercritical Fluids, vol.66, pp.86-95, 2012.

[25] AOCS, "American Oil Chemists' Society", Urbana, IL - USA, 2009.
[26] V. L. Singleton, J. A. J. Rossi, "Colorimetry of total phenolics with phosphomolybdic-phosphotungstic acid reagents.", American Journal of Enology and Viticulture, vol.16, pp.144-158, 1965.

[27] V. L. Singleton, R. Orthofer, R. M. Lamuela-Raventos, Analysis of total phenols and other oxidation substrates and antioxidants by means of Folin-Ciocalteu reagent, pp.152-178, in: Oxidants and Antioxidants, Pt A, L Packer (Ed.), 1999.

[28] FAO/WHO, "Combined compendium of food additive specifications", Food and Agriculture Organization of the United Nations, vol.3, pp.11, 2006. 